\title{
SLOVENIJA V GLOBALIZACIJSKI PASTI
}

\author{
Marijan M. Klemenčič ${ }^{*}$
}

\section{Izvleček}

Prispevek predstavlja značilnosti globalizacije, predvsem na gospodarskem področju. Osrednja pozornost je namenjena družbenogospodarskemu in prostorskemu razvoju Sloveniji $v$ globalizacijskih procesih; izpostavljene so njene razvojne možnosti in dileme.

Ključne besede: Globalizacija, Slovenija, lokalnost, osrednje območje, periferno območje

\section{SLOVENIA IN THE TRAP OF GLOBALIZATION}

\section{Abstract}

The article represents characteristics of globalization, particularly on economic field. Special attention is focused on socioeconomic and spatial development of Slovenia in globalization processes; its development possibilities and dilemmas are pointed out.

Key words: Globalization, Slovenia, locality, central area, peripheral area

\footnotetext{
* Dr. izred. prof., Oddelek za geografijo, Filozofska fakulteta Univerze v Ljubljani, Aškerčeva 2, SI 1000 Ljubljana, Slovenija
} 


\section{UVOD}

Slovenija se od 90. let dalje pospešeno vključuje v svetovne gospodarske tokove. Z njeno vključitvijo $\mathrm{v}$ Evropsko zvezo bo na vseh področjih dokončno vržena $\mathrm{v}$ kruto mednarodno konkurenco, ki jo usmerja globalizacija.

Namen prispevka je na kratko predstaviti vsebino globalizacije in nakazati pripravljenost Slovenije na njene izzive. Ne prva in ne druga naloga ni lahka, saj še zdaleč ni enotnega mnenja o vsebini globalizacije, pa tudi ne o potrebnem odzivu Slovenije nanjo. Glavno spoznanje, do katerega pridemo ob pregledu modelnih prikazov preobrazbe sodobnega sveta namreč je, da so predstave posameznih avtorjev različne; tako da še ne moremo govoriti o splošno sprejeti razvojni paradigmi. Dejavniki, ki bistveno vplivajo na spreminjanje sveta, so namreč vse številnejši in vse bolj prepleteni med seboj, zaradi česar je slika razvoja sveta vedno bolj zapletena. Lahko rečemo, da je svet »odet v plašč številnih (delnih) resnic«. Takšno stanje lahko vodi raziskovalce $\mathrm{v}$ dve skrajnosti: $\mathrm{v}$ pretirano posploševanje, ali pa $\mathrm{v}$ zanikanje potrebe po iskanju občih potez (pravilnosti).

\section{GLOBALIZACIJA}

Izraz globalizacija, ki se je pojavil v 80. letih v ZDA in na Japonskem, po Dollfusu (1995) predstavlja tri skupine procesov:

- odločno popuščanje držav gospodarskemu liberalizmu (nižanje carin),

- širjenje delovanja velikih družb na ves svet,

- splošna uporaba telekomunikacij.

Isti avtor označuje globalizacijo kot zmago »omrežja mrež«: finančnih, informacijskih, letalskih itn. Nekatera območja so bolj »omrežena«, druga manj, ali pa ostajajo »V senci«. Najbolj gosto so te mreže razpredene na »otokih svetovnega metropolitanskega otočja « (Dollfus, 1995). Metropolitanska območja (na primer New York, Tokio, London) so postala svetovna »živčna središča« ali »hrbtenjača« razvoja sveta. Z razvojem gospodarstva, financ in vseh oblik prometa postajajo nosilci sodobne (svetovne) civilizacije.

Reich (1991) trdi, da živimo $\mathrm{v}$ prehodnem obdobju; v prihodnjem stoletju ne bo državnih proizvodov ali tehnologij, družb, industrij, niti ne državnih gospodarstev. Proizvodni dejavniki (denar, tehnologija, tovarne, oprema) brez napora prehajajo državne meje. Tako postaja tudi ideja ameriškega gospodarstva, ameriške družbe, kapitala, tehnologije, izdelkov brez pomena. Razvoj naj bi šel v smer popolne globalizacije, ko naj bi pridevnik »ameriški« dobil globalni, vsezemeljski pomen. 
Thompson in Hirst (1992) sta bolj skeptična. Na temelju empiričnih raziskav ugotavljata, da nimamo polno globaliziranega gospodarstva. Trdita, da izraza globalnost in lokalnost nimata za vselej določene vsebine, saj imata različen pomen za podjetja in za države. Oba dejavnika se zaradi različnih funkcij obnašata različno: podjetja izrazito podjetniško, to je profitno, država pa v večji meri socialno.

Čeprav se zdi globalizacija realno dejstvo, pa nekateri menijo drugače: »Globalizacija, globalni sistem itn. so izrazi, ki jih na široko uporabljajo politiki, znanstveniki in mediji, vendar se ne nanašajo na materialne, otipljive pojave, ki bi se lahko skladali s temi izrazi. Globalizacija je družbeni konstrukt, ki se uporablja kot primerna prostorska metafora za razumevanje, razlago in uzakonitev izkušenj« (Kelly, 1997). S tem ne mislimo relativizirati pojma globalizacija, pač pa le pokazati na širino njegove vsebine oziroma na njegovo premalo jasno opredelitev; ta je v tem trenutku nemogoča, saj so predstave raziskovalcev o vsebini in naravi globalizacije preveč različne.

\section{GOSPODARSTVO IN GLOBALIZACIJA}

Zadnji dve stoletji svet doživlja močan razvoj gospodarskega poenotenja. Prvi nosilec tega razvoja je bila Velika Britanija kot prva industrijska velesila in država, ki je obvladovala svetovna morja. »Pax britanica« nekateri poimenujejo obdobje britanske prevlade v svetovni trgovini. Že pred drugo svetovno vojno, zlasti pa po njej se je pojavil naslednji nosilec gospodarskega razvoja sveta: ZDA. Za »Pax americana« se označuje obdobje nadvlade ZDA kot svetovnega bankirja. Njihova moč začne bledeti z gospodarskim uveljavljanjem Japonske in EGS. Velesile so se morale začeti dogovarjati o splošnih pogojih delovanja svetovnega trga. Tako imenovana »urugvajska runda« nakazuje uveljavljanje načela proste mednarodne trgovine. Razumljivo je, da imajo od tega koristi gospodarsko najmočnejše države.

K polnemu uveljavljanju globalizacije je pripomogel fordistični način proizvodnje, ki ga nekateri imenujejo tudi obdobje gospodarskega megalomanstva. Za ta način proizvodnje, ki sta ga omogočila tekoči trak v začetku 20. stoletja in prazno svetovno tržišče, so značilne naslednje poteze: togost, masovna proizvodnja, standardizirani izdelki, velike zaloge, priučena delovna sila, vertikalna aglomeracija, globalne družbe.

Ko se je svetovni trg napolnil s standardiziranimi izdelki, so morali proizvajalci iskati nove prodajne možnosti, predvsem s prilagajanjem zahtevam trga. Tako sodobno, pofordistično gospodarstvo označujejo: prilagodljivost, maloserijska proizvodnja, prilagodljiva strojna oprema, pestri izdelki, minimalne zaloge, stalno izobraževanje, vertikalna dezintegracija (Clark \& Holly, 1996).

Seveda pa $\mathrm{v}$ svetu nastopata oba gospodarska koncepta. Bolje rečeno: za veliko večino sodobnega gospodarstva je značilno prepletanje obeh konceptov. To še 
posebno velja za slovensko gospodarstvo, ki je bilo v 90 . letih pospešeno vrženo $\mathrm{v}$ konkurenčni boj na svetovnem tržišču.

Nosilec svetovne trgovine so predvsem multinacionalne družbe, ki jih zato mnogi smatrajo za hrbtenico svetovnega gospodarstva ali za nosilce globalizacije. Multinacionalne družbe s proizvodnjo in trženjem, ki sta do skrajnosti racionalizirana in agresivna, postavljajo kriterije ostalemu gospodarstvu. Dickinson (1994) si takšno sodobno gospodarstvo predstavlja $\mathrm{v}$ obliki verig, tako proizvodnje, blaga, vrednosti in dodane vrednosti. Na ta način je predstavljena celovitost prepletenosti in soodvisnosti svetovnega gospodarstva.

\section{GLOBALNO IN LOKALNO}

Brisanje državnih meja in regionalnih posebnosti zaradi (gospodarskega) poenotenja sveta daje globalizaciji značaj nevtralnosti, težnje, da poenoti vse, kar je vanjo vključenega. Tržni triumfalizem namreč potiska na rob alternativne načine bivanja $\mathrm{v}$ svetu. Tako lahko sklepamo po Featherstonu (1993), da so v globalizaciji kraji in kulture lahko postavljeni v vzdolžni smeri, eden poleg drugega, brez hierarhičnega razlikovanja.

Če na to dejstvo (izjavo) pogledamo z nekoliko širšega (filozofskega) zornega kota, takoj ugotovimo, da mora globalnost (splošnost) za svojo uresničitev imeti nasprotje, to je lokalnost (posebnost). Teoretično lahko rečemo, da je uveljavljanje globalizacije hkrati promocija lokalnosti. Država kot donedavni usodni uravnalec gospodarstva na svetovni ravni in življenja na lokalni ravni, je izgubila precej nekdanje moči: v prvem primeru so pridobile na pomenu nadnacionalne družbe, $\mathrm{v}$ drugem pa lokalna (regionalna) samouprava.

\section{SREČA ALI NESREČA GLOBALIZACIJE?}

Industrializacija kot začetnik globalizacije je - prek razvoja prometnih sredstev - v dobršni meri poenotila gospodarski sistem, hkrati pa povzročila nove regionalne razlike. O določeni obliki globalizacije (poenotenja sveta) lahko govorimo tudi za obdobje pred industrializacijo. Takratna gospodarska enotnost sveta, ki jo je opredeljevala močna prevlada kmetijstva, je bila na zunaj pestra, pač glede na oblike kmetovanja. Različnost kmetovanja je bila posledica predvsem različnih naravnih pogojev za kmetijstvo. Poselitev je bila izrazito razpršena. Kulture, vezane predvsem na kmetijske sisteme, so bile zelo pestre. Stare civilizacije so izražale živ odnos družbe do narave in jih zato lahko pogojno imenujemo naravne. 
Novo gospodarsko poenotenje sveta, ki ga povzroča industrializacija, sloni na tehnološkem razvoju. Gospodarski zakoni, ki zahtevajo standardizirano in racionalizirano proizvodnjo, so prepojili celotno družbeno bit. Potrošništvo je postalo temelj sodobne civilizacije, ki jo imenujemo zahodna ali tudi ameriška. Njen zunanji izraz je enostavnost, enotnost oziroma zavračanje in celo uničevanje posebnosti (različnosti). Ta navidezna enotnost pa je prinesla novo razlikovanje - glede na količinske kazalce (razlike v materialnem bogastvu). Svet in njegovi posamezni deli se razlikujejo po stopnji gospodarskega razvoja. Nova civilizacija je, $\mathrm{v}$ nasprotju $\mathrm{s}$ predhodno, tehnizirana, odtujena od narave. Njena usoda ni odvisna od vremenskih razmer, ampak od gibanja borznih indeksov.

Reakcija dobršnega dela sodobne družbe na način življenja zahodne civilizacije kaže, da je le-ta slepo črevo v nizu razvoja civilizacij. Vse bolj se uveljavlja vrednost »naravnosti« in s tem tudi vrednote predhodne civilizacije.

\section{VPLIV GLOBALIZACIJE NA PROSTORSKI RAZVOJ}

Robnost (perifernost) in obrobnost (marginalnost) sta zgodovinski stalnici slovenskega ozemlja vsaj zadnji dve tisočletji. Slovenci smo bili večinoma (razen v začetku naselitve in po letu 1990) objekt v rokah velikih sil na robu njihovega ozemlja (Habsburžanov, Madžarov, Benečanov). Zaradi tega smo bili v stalnem zaostanku: v razvoju gospodarstva, družbe, tehnike in posledično tudi v prostorskem razvoju.

Kako se Slovenija danes povezuje s svojim sosedstvom? Večina njenih meja spada med tradicionalne »geografske« meje, torej takšne, ki na jasen fizičen način ločujejo dve državi (gorovja, reke, gozdovi). Obmejna območja sosednjih držav so manj razvita $\mathrm{v}$ okviru domačih držav in $\mathrm{v}$ velikem delu tudi manj razvita od slovenske strani. Izjeme so vezane le na večja mesta na drugi strani meje (Trst - Gorica, Gradec, Zagreb). Tako je za Slovenijo kot državo značilna jasna fizična razmejenost do sosedstva; njena velikost je takšna, da v odnosu do evropskih držav funkcijsko lahko nastopa kot regija, v odnosu do globalizma pa le kot lokalna stopnja.

Oglejmo si nekatere značilnosti prostorskega razvoja v Zahodni Evropi in Sloveniji. Izhajajmo iz splošnih družbenogospodarskih sprememb, ki jih je doživel svet $\mathrm{v}$ zadnjih stoletjih od agrarne do postindustrijske družbe.

1. Zahodna Evropa je bila vključena $\mathrm{v}$ same začetke sodobne globalizacije. Konkurenčni boj v gospodarstvu je v prvem obdobju povzročil zgoščevanje industrije in prebivalstva na manjših območjih in praznenje podeželja. V drugem obdobju se je posodobilo kmetijstvo, urbanizacija pa je postala najpomembnejši prostorski razvojni element. Razvoj perifernega kapitalizma (selitev industrije, predvsem bazične, v 
Tretji svet) je omogočil pospešeno terciarizacijo družbe in razvoj suburbanizacije. Gospodarsko manj razvita območja so deležna skrbi države. Oblikovala so se središča moči (finančne, gospodarske, poltične), hkrati pa so se tam izoblikovala prometnokomunikacijska in informacijska vozlišča (London, Pariz, Frankfurt, itn.). Suburbanizacija se širi in dobiva elemente deurbanizacije. Podeželje je kmetijsko visoko specializirano, razvijajo se različne oblike turizma, predvsem rekreacijskega.

2. V Sloveniji je bila industrializacija zakasnela in šibka, zato je bila urbanizacija skromna. Povojna, ideološko pospeševana industrializacija (bolje proletarizacija slovenske družbe) zaradi razvoja prometnih sredstev in ohranjanja stare (srednjeveške) posestne strukture tudi tokrat ni imela za posledico močne urbanizacije. Potreba novih industrijskih delavcev (polkmetov) v prvih desetletjih po drugi svetovni vojni, da na zemlji dobijo del zaslužka ali pa da ohranjajo obdelavo zemlje zaradi starosvetnega odnosa do nje, se proti koncu 20. stoletja navezuje na pojem kakovosti življenja, ki ga nudi bivanje na podeželju. Pri tem je pomembno bivalno okolje, pa tudi možnost pridelave zdrave hrane.

Za slovensko poselitev tako lahko rečemo, da je dokaj srečno preskočila (prehodno) obdobje industrializacije in pretiranega zgoščevanja poselitve. Tako je iz gospodarskih razlogov razpršena srednjeveška poselitev Slovenije našla kontinuiteto v želji sodobne družbe po kakovostnem bivalnem okolju, ki ga taka poselitev nudi, sodobna prometna (telekomunikacijska) sredstva pa omogočajo.

Prepričani smo, da bi morala državna politika pri poselitvi najti ravnotežje med zahtevami prebivalcev po kakovostnem življenskem okolju (razpršeno poselitvijo) in interesom države po racionalni (zgoščeni) poselitvi. S tem bi razbremenili najbolj privlačna območja (gospodarsko, prometno, turistično) in dosegli večjo stopnjo samovzdrževanja robnih območij.

\section{MAJHNA SLOVENIJA V VELIKEM SVETU}

Če na slovensko gospodarstvo pogledamo s svetovnega prostorskega vidika, jo moramo obravnavati kot »del mreže, znotraj katere medsebojno učinkujejo delna svetovna gospodarstva« (Dickens, 1994). Položaj v mreži opredeljujejo različne stopnje in oblike moči ter vplivov. Tudi za Slovenijo je pomembno, da kot vsa druga lokalna gospodarstva lahko le upa, da bo udeležena v novih integriranih mrežah. Kaj pa to pomeni za Slovenijo, za njeno samobitnost in za njen razvoj?

Diskusije o gospodarski suverenosti Slovenije se v globalizacijskih procesih zdijo nesmiselne, kar lahko pripelje do usodne apatije. Pogosto lahko slišimo, da je slovensko gospodarstvo majhno, neznatno, zato neprepoznavno v svetovnem okviru. Ali je upravičen strah posameznih strokovnjakov, da bi slovensko gospodarstvo $\mathrm{s}$ polno vključitvijo v evropsko (svetovno) gospodarstvo propadlo? Nekateri zmotno 
pričakujejo, da mora Slovenija postati enakovredna partnerica gospodarskim (vele)silam, če hoče obstati. Na drugi strani pa zelo redko slišimo vprašanje, kaj si Slovenija sploh želi od vključevanja v svet in kakšne so njene možnosti, prednosti. Med prednostmi zelo radi izpostavljamo geografsko lego Slovenije kot njeno temeljno razvojno odliko. Kako smo jo pa izkoristili? Se prometna prehodnost Slovenija odraža na železniški postaji v Ljubljani, ali na brniškem letališču, ali na avtocestnem omrežju? Ugodna geografska lega bo prednost Slovenije šele takrat, ko jo bomo znali učinkovito tržiti.

Očitno je, da so vsa prizadevanja slovenske države za vstop v Evropsko zvezo vezana na gospodarsko področje. Kako, če sploh, bodo pri tem prizadeta narodna, regionalna in lokalna samobitnost?

Za oblikovanje strategije celovitega razvoja Slovenije je prav gotovo najprimerneje iskati izhodišča pri pokrajinskih značilnostih Slovenije.

Pestrost, razpršenost, drobna razčlenjenost so pridevniki za oznako naravnih razmer. Prepletenost struktur, preostanki preteklosti označujejo družbenogospodarske razmere.

V strokovni literaturi se že dlje časa poudarja pomen aktiviranja lastnih moči na nekem območju, šele za tem pride v poštev tuj kapital ali znanje. Z razvojem domačih potencialov in s tujim kapitalom/znanjem se krepi lokalna kolektivnost, kar je predvsem za Slovenijo druga, ugodnejša plat globalizacije.

Druga ugodna poteza Slovenije v globalizaciji je lokalnost. Na območjih s približno $100 \mathrm{~km}$ polmerom (kar naj bi bil obseg lokalnega območja) se lahko oblikuje tekmovalnost, komplementarnost gospodarskih dejavnosti, konkurenčnost med proizvajalci $\mathrm{v}$ isti panogi. $\mathrm{V}$ takih pogojih je možna raznovrstna dejavnost, tudi proizvodnja tehnološko najbolj zahtevnih izdelkov in storitev. Razen za predelovalno industrijo niso potrebne domače surovine. Bolj kot inflacija ali šibkost domače valute je za gospodarski uspeh odločilna kakovost podjetniškega kadra (Dollfus, 1995).

Kaj v geografskih očeh manjka Sloveniji za uspešen celovit razvoj razen (razgledanega, pogumnega) kadra?

\section{LITERATURA}

- Clark A. E., Holly B. P., 1996: The organization of production in high technology industries: an empirical assessment. The Professional Geographer, 2, s. $127-139$.

- Dickens P., 1994: The Roepke lecture in economic geography global- local tensions: firms and states in the global space-economy. Economic Geography 70, 2, s. $101-128$. 
- Dollfus O., 1995: Mondialisation, competitivites, territoires et marches mondiaux. L,Espace Geographique 24, 3, s.270-280.

- Featherstone M., 1993: Global and local cultures. V: Mapping the futures: local cultures, global change. Ur. Bird J., Routledge, London.

- Hirst P., Thompson G., 1992: The problem of »globalization«: international economic relations, national economic management and the formation of trading blocs. Economy and Society 21, s. $357-397$.

- Kelly P. F., 1997: Globalization, Power and the Politics of Scale in the Philippines. Geoforum 28, 2, s. 151-171.

- Reich R., 1991: The work of nations: preparing ourselves for $21^{\text {st }}$ century capitalism. New York, Vintage books.

\title{
SLOVENIA IN THE TRAP OF GLOBALIZATION
}

\begin{abstract}
Summary
Contemporary economy (production, goods, value, added value) should be, according to Dickinson (1994), organized in form of chains. With such form wholeness of interlacement and codependence of the world economy is presented. It is important also for Slovenia to hope, as well as all other local economies, to be presented in new integrated networks. Peripheral and marginal position are presenting historical constancies of Slovene area in at least last two millenniums, which results in permanent arrearage, meaning development of economy, society, technics as well as spatial development. However it seems as if still preserved Middle-Aged pattern of settlement has to a great extent acquired new function in the area of globalization, when quality of life is being so important.

Landscape characteristics of Slovenia would be the most suitable starting points for formation of the strategy of integral development of Slovenia in the process of globalization. Variability, dispersion and tiny dismemberment are characteristics of natural conditions. Interlacement of structures and strong remains from the past are characterizing socioeconomic and spatial conditions. In global extensions Slovenia is holding typical features of a local area with numerous satisfactory development features. It seems like lack of capable managing (business) cadre represents the main development weakness of Slovenia.
\end{abstract}

